\title{
Teaching Co-Design to Promote Students' Community Engagement
}

\author{
Wiryono Raharjo ${ }^{1, *}$ \\ ${ }^{1}$ Department of Architecture, Faculty of Civil Engineering and Planning, Universitas Islam Indonesia, Indonesia
}

\begin{abstract}
The current landscape of architectural education has been predominantly based on studio teaching the mode of teaching that can be traced back in the age of French L'Ecole des Beaux Arts. It was during the Beaux Arts era that studio teaching and jury system first deve-loped, and it continues today. The approach is characterized by the use of atelier (studio) for coaching, where juniors learn from seniors and competition among students are the norm. The approach also presumes that architects are the provider of design services who think that they are more competent than their clients in solving the design problem; which is a paradox to the fact that most parts of the built environment anywhere in the world are the creation of ordinary people. In other words, ordinary people can contribute significantly to the decision making within the architectural design process. They can actually be treated as a partner of architects in designing their building, which is what Co-Design all about. This paper aims to describe the introduction of Co-Design approach in architectural design studio teaching at Universitas Islam Indonesia. The research questions this paper intends to respond: to what extent could Co-Design be adopted in architectural design teaching? What lessons have the students learned from their experience in involving people in the urban design process? The case study methods employed in this research, through which author looks at the CoDesign teaching delivery in the Architectural Design Studio 7 in the past three years. While overall result of the study shows that time limitation has constrained the students' community engagement, most cases examined reveal that introduction of Co-Design approach has paved the way for students to understand how ordinary people contribute to the shaping of the urban built environment.
\end{abstract}

Keywords: Community Engagement, Urban Co-Design, Kampung

\section{Introduction}

Since the age of L'Ecole des Beaux-Arts, architectural education all over the world has been predominantly based on studio teaching. Donald Schön (1987) uses the term "coaching" to call the mode of teaching in the studio where students are guided by a coach in the gradual process of learning to design. In such mode of teaching the coach is usually a more senior person, either a lecturer or a teaching assistant, who stimulates dialogue with students to "reframe" the design problems (Schön, 1987). Often the dialogue between students and their coach (mentor) mimics the dialogue between architect and client, where student acts as an architect while mentor plays the role as a client (Raharjo, 1993).

However, studio teaching also sees the client as a person to be served by the architect. While the end results subject to client's approval, such situation assumes the superiority of architect in running the design process. It disregards the fact that most parts of the built environment are not designed by the architect. In other words, ordinary people have the capacity to contribute significantly to the making of the built environment. They are the designer by nature, whose voices shall be taken into account. These people can be treated as the partner of the architect in conducting the design process, which leads to the egalitarian relationship between architect and client. Within the broad range of design literature, such design approach is often termed Co-Design.

Co-Design frequently appears as "an umbrella term for participatory, co-creation, and open design processes" (Chisholm in http://www.designforeurope.eu/what-co-design accessed on 30 September 2017). It places the central role of clients in the decision-making within the design process.

This paper describes how Co-Design approach is adopted in the architectural design studio teaching. It intends to respond to the following questions:

1. To what extent can co-design approach be adopted in architectural design teaching?

2. What lessons have the students learned from involving the people in making design decision?

The research was conducted through empirical observations of teaching activity and the environment of the Architectural Design Studio (ADS) 7- a course delivered within the Department of Architecture, Faculty of Civil Engineering and Planning, Universitas Islam Indonesia (UII). The teaching documents observed are those delivered in the past two years (2015 and 2016), but the ongoing course (2017) is also examined to enhance the analysis.

\footnotetext{
Corresponding author: raharjo@uii.ac.id
} 


\section{Co-Design: review of related literature}

Co-Design is about making consensus among people in deciding the best choice of design (Day, 2003). There are two among many definitions of Co-Design this paper considers essential. The first one is by Barrie and Edwards (2003:10), who writes that Co-Design is “... the process of deliberately engaging users of the system, deliverers of services and other experts, being led by experts such as designers, to actively understand, explore and ultimately change a system together". Another definition is suggested by Hagen (2014), which says that Co-Design is the involvement of the community in the design process as active participants, to create shared value.

The root of Co-Design can be traced back in the 1960s in Britain when community participation began to emerge as a norm in design. The British Housing Act (passed in 1969) stated that people must be consulted during the preparation of the plan, not after the plan is ready (Day, 2003). Co-Design has been integrated into the development public services in Australia and New Zealand since the 1990s (Barrie \& Edwards, 2013). A series of key terms that embody CoDesign are communicated, consult coordinate, and collaboration (Barrie and Edwards, 2003). Barrie and Edwards (2003:11) further mention that "Co-Design is an approach that can be utilized in a range of design disciplines and processes", while Myers (2012) writes that Co-Design is about collective thinking, a collaborative action of design between client, designer, and end user.

The approach can be regarded as the root of various other design approaches as depicted in Table 1. It has also been adopted in various fields, from automobile design to urban housing (see for example Albinsson, Lind, and Forsgren, 2007; Rodriguez and Astrand, 1996).

Table 1. The scope of Co-Design (adapted from Hagen, 2014).

\begin{tabular}{|c|l|}
\hline No. & \multicolumn{1}{c|}{ Co-Design related areas } \\
\hline 1 & Participatory action research \\
\hline 2 & Participatory design \\
\hline 3 & Social design \\
\hline 4 & Transformation design \\
\hline 5 & Co-production \\
\hline 6 & Service design \\
\hline 7 & Community consultation \\
\hline 8 & Open innovation \\
\hline 9 & Collaborative inquiry \\
\hline 10 & Design thinking \\
\hline 11 & Design for social innovation \\
\hline 12 & Change management \\
\hline 13 & Experience-based design \\
\hline
\end{tabular}

The process of Co-Design varies according to the field and complexity of the design problems, as well as the number clients, i.e., members of the community involved in the design. In the field of urban housing, as experienced by Rodriguez and Astrand (1996), the process typically begins with initial contact between designer and the future clients. The objective of initial contact is to make sure that these clients are prepared to engage in the design process. When designer and clients are ready to collaborate, the design process may follow any methods agreed by both parties.

The literature reviewed above mostly discuss the experiences of implementing Co-Design in the real design environment. None of them actually deals with how CoDesign is taught within the academic setting.

\section{Teaching Co-Design: the methodology}

As mentioned earlier, the course used as a medium of CoDesign delivery is Architectural Design Studio (ADS) 7. It is a mandatory course offered in the Department of Architecture, Universitas Islam Indonesia (UII) to the fourth year students. This course may be more appropriate to be termed "Urban Design Studio" since its content is mainly about the practice of urban design process. It is the end of a series of ADS courses prior to the commencement of Bachelor Final Project.

In the past three years, the average number of architecture students attending ADS 7 is ranging between 140 and 150 persons. This year (2017), the total number of lectures coaching ADS 7 is 10, each of them handles a maximum of 15 students. Therefore, there are 10 classes running ADS 7 simultaneously. Two of this classes, including author's class, is assigned to introduce Co-Design in the design exercise delivered to the students.

There were 15 students in author's class both in 2015 and 2016, as well as in 2017. In the first week of the semester, the author typically asked students to work in a team of maximum 5 members. The reason for making students work in a team is to accelerate the process of finding clients due to the limitation of time. In addition, it also made students more confident in communicating with people who would be chosen as their clients. However, this teamwork only valid for the first half of semester; students must work individually thereafter until the final submission of their works at the end of the semester.

This paper looks at the cases of Co-Design delivery in 2015, 2016, and the ongoing ADS 7 in 2017. It reviews the samples of work of students in ADS 7. The samples are selected using purposive sampling methods, where author selects these samples based on the quality of works as indicated by the final grade obtained by students, in addition to the characteristics of settlements used by students as their case study. Furthermore, the selected work is examined based on how students practice the Co-Design, by looking at the length of initial contact (LOIC) with the targeted clients, the length of community engagement (LOCE), and the Number of Clients (NOC).

\section{Case study analysis and findings}

The urban areas chosen by students for their case studies (Table 2) indicate two types of settlements, i.e. formal and informal (kampung). While formal settlements often called kampung as well, in this paper author defines the informal kampung as a settlement that emerged from the illegal subdivision of government managed land. The formal kampung, such as Kotagede and Kauman, occur as a result of the accumulation of individually designed on housing on unplanned plots but with legal tenure. 
Table 2. Types of targeted settlements chosen by the design teams.

\begin{tabular}{|l|c|c|}
\hline \multicolumn{1}{|c|}{ Year } & $\begin{array}{c}\text { Formal } \\
\text { Kampung }\end{array}$ & $\begin{array}{c}\text { Informal } \\
\text { Kampung }\end{array}$ \\
\hline 2015 & 2 teams & 1 team \\
\hline $2016(*)$ & 2 teams & 2 teams \\
\hline 2017 & 1 team & 2 teams \\
\hline
\end{tabular}

(*) There were 4 teams in 2016, two of them consisted of 3 and 2 members; the rest consisted of 5 members.

\section{Cases}

The year of 2015 marked the beginning of Co-Design application in teaching architectural design studio at UII. As depicted in Table 2, the 2 teams have selected formal kampung. One of the works received A grade of this category belong to a student named NAL, which focuses on the development of urban farming in Cepit Community. As stated in the preceding section, the number of clients (NOC) she and her team found, the length of initial contact (LOIC), and the length of community engagement (LOCE) are indicators that author uses to measure the Co-Design performance. Table 3 shows the comparison between Sample 1 (NAL) and Sample 2, which belongs to a student named BS. Sample 2 represents informal settlement. In this case, BS and his team investigated Kampung Gowok, an informal settlement on Gajahwong Riverbank.

Table 3. Comparison of two cases (2015).

\begin{tabular}{|c|c|c|c|}
\hline $\begin{array}{c}\text { Student's } \\
\text { name }\end{array}$ & NOC & $\begin{array}{c}\text { LOIC } \\
\text { (Weeks) }\end{array}$ & $\begin{array}{c}\text { LOCE } \\
\text { (Weeks) }\end{array}$ \\
\hline $\begin{array}{c}\text { NAL } \\
\text { (Formal } \\
\text { Kampung) }\end{array}$ & 5 & 4 & 6 \\
\hline $\begin{array}{c}\text { BS } \\
\text { (Informal } \\
\text { Kampung) }\end{array}$ & 4 & 2 & 13 \\
\hline
\end{tabular}

Note: NOC $=$ Number of Client; LOIC = Length of Initial Contact; LOCE $=$ Length of Community Engagement.

The above findings show that length of initial contact (LOIC) performed by BS is shorter than that of NAL. Author's observation suggests that BS could achieve such LOIC because he had developed a relationship with the community prior to the commencement of the course. He was involved in an NGO called Arkom (Arsitek Komunitas Community Architect), which had been engaged with Kampung Gowok community for some time. For BS, the LOIC explains the length of time needed to consolidate the clients and his team members.

The length of community engagement (LOCE) for BS is also longer than that of NAL. This was because BS continued to get involved with Arkom in addition to working on the ADS assignment even beyond that, since he further used the above case for his Bachelor Final Project. However, NAL and her team could get 5 clients, ranging from formal neighborhood leader ( $\mathrm{RW}^{1}$ Chief) to a businessman. This shows that NAL team was able to overcome their challenge of client finding.

\footnotetext{
${ }^{1}$ RW stands for Rukun Warga (Community Association).
}

\section{Cases}

In 2016, Co-Design continued to be adopted in the ADS 7 assignment with the same delivery method, but students are not allowed to choose the same area as that of the previous year.

Table 4 shows two samples taken for analysis. The first sample is the work of HAU, which represents the case of formal kampung called Prawirotaman - well-established settlement in southern part of Yogyakarta that has been experiencing gentrification in the past 3 decades as a result of the tourism industry. The second sample is the work of YSA and his team, who chose to work on informal kampung called Ratmakan. This kampung is located in the center of Yogyakarta, on the Chode riverbank.

Based on the findings depicted in Table 4, we can see that HAU and her team took a longer duration in both finding NIC and LOCE compare to that of YSA. However, she obtained smaller NOC than YSA's. Author observation during teaching suggests that HAU and her team faced difficulties in finding the appropriate clients. The longer LOCE in her case was due to the team's struggle in finding what exactly the community wants to achieve for making Prawirotaman a better kampung. Furthermore, team's observation informs that despite the fast pace of tourism industry within this kampung, the community is getting more fragmented.

Table 4. Comparison of two cases (2016).

\begin{tabular}{|c|c|c|c|}
\hline $\begin{array}{c}\text { Student's } \\
\text { name }\end{array}$ & NOC & $\begin{array}{c}\text { LOIC } \\
\text { (Weeks) }\end{array}$ & $\begin{array}{c}\text { LOCE } \\
\text { (Weeks) }\end{array}$ \\
\hline $\begin{array}{c}\text { HAU } \\
\text { (Formal } \\
\text { Kampung) }\end{array}$ & 3 & 5 & 10 \\
\hline $\begin{array}{c}\text { YSA } \\
\text { (Informal } \\
\text { Kampung) }\end{array}$ & 6 & 4 & 8 \\
\hline
\end{tabular}

Note: NOC $=$ Number of Client; LOIC = Length of Initial Contact; LOCE $=$ Length of Community Engagement.

The work of YSA and team on Kampung Ratmakan shows a shorter LOIC and LOCE than that of HAU, however, YSA and team gained more NOC. Author observation during teaching suggests that such achievement was due to the active role of the key player in Ratmakan development, i.e. the young and energetic Head of RT $07^{2}$. This person had opened access to the team, which led to the gaining of 6 NOC. The access also enabled the team to attend several community gatherings to discuss how kampung Ratmakan mitigate the flood disaster.

\footnotetext{
${ }^{2}$ RT stands for Rukun Tetangga (Neighborhood Association), the smallest level of governance in Indonesia. Association of several RT forms the RW (Rukun Warga - Community Association)
} 


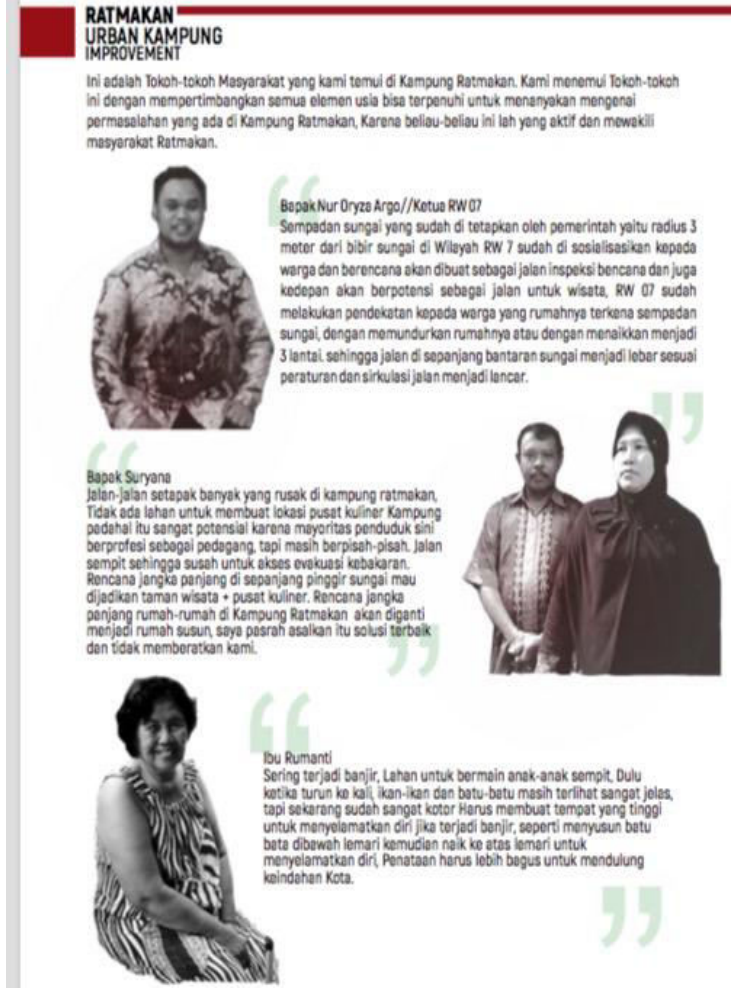

Fig. 1. Part of client profiling by YSA.

\section{The ongoing studio in 2017}

While the ADS course of 2017 batch is still running at the moment, the author sees it is pertinent to include the studio observation notes in this paper to enhance the analysis. The class shows a typical character of informal settlement chosen as the design target, i.e., the settlement is located on the riverbank, while the formal settlement is located in a mix of residential and commercial area. Students have decided to form 3 teams of 5 members. The composition of the team is depicted in Table 5.

Table 5. Composition of team and ongoing NOC.

\begin{tabular}{|c|c|c|c|}
\hline Team Name & NOC & $\begin{array}{c}\text { Formal } \\
\text { kampung }\end{array}$ & $\begin{array}{c}\text { Informal } \\
\text { kampung }\end{array}$ \\
\hline Jogoyudan & 3 & & $\sqrt{ }$ \\
\hline Ngampilan & 3 & & $\sqrt{ }$ \\
\hline Kaliwaru & 2 & $\sqrt{ }$ & \\
\hline
\end{tabular}

Note: $\mathrm{NOC}=$ Number of Clients.

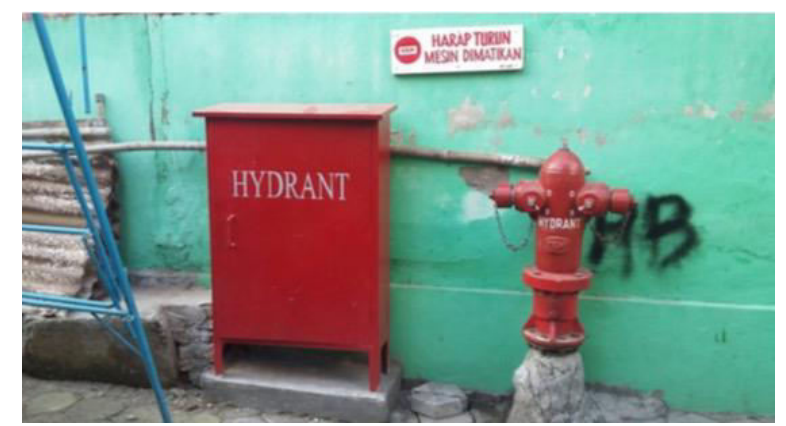

Fig. 2. Hydrant installation - an existing example of government intervention to disaster mitigation at kampung Ngampilan.

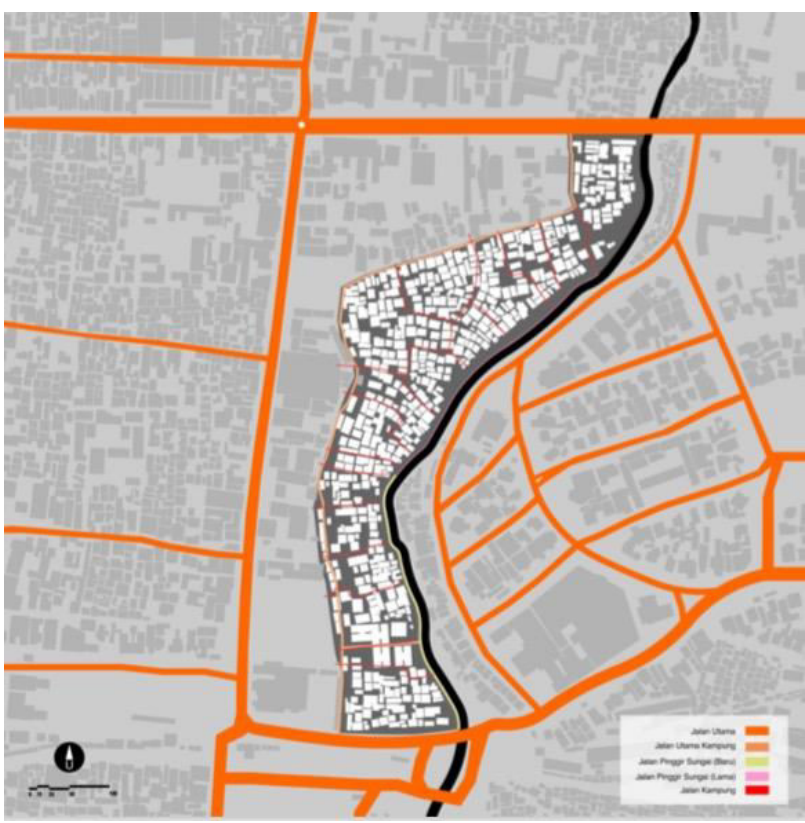

Fig. 3. A morphological map of informal kampung made by Jogoyudan team.

Table 5 shows the composition of the team and targeted kampung. The number of informal kampungs chosen, which exceeds the formal one, indicate that that informal kampung has been the preferred design target since the first delivery of Co-Design teaching in 2015. The average number of NOC gained in the case of informal kampung is higher than the formal one, despite its complex social and physical characters, presumably because the informal kampung tends to get more attention from the government and aid agencies through various improvement programs, which makes the community familiar with the process of action planning.

\section{Conclusion}

In response to the research questions stated earlier, the author argues that ideal Co-Design process is rather unrealistic to be applied in architectural design teaching. This is partly due to the limitation of teaching period, which in average last for 14 weeks, whereas time consumed for finding clients and engaging in the Co-Design process is unpredictable. For example, Table 5 shows that one of the design teams, i.e. Kaliwaru Team, could only gain 2 NOC within 7 weeks. NOC is an indication of the robustness of the Co-Design, the higher NOC involved in the design process will give more assurance in getting the right design decision.

Through discussions during design coaching, the author noted that introduction of Co-Design provides opportunities for students to directly observe the community needs. Students also learn how to select the reliable clients, who are not always formal leaders. The findings also suggest that previous experience in community engagement contribute to the gaining of shorter LOIC, which may give more room for the discussion on design process between students (designer) and clients. In other words, the shorter LOIC may lead to the longer LOCE. 
Furthermore, the analysis also suggests that gaining the NOC in an informal settlement is relatively faster than that of formal settlement. The familiarity of public and private intervention in informal settlement seems to make access to the community easier than gaining NOC in the formal settlement.

This paper has proposed some new terminologies, i.e. LOIC (Length of Initial Contact), LOCE (Length of Community Engagement, and NOC (Number of Clients) to be used as indicators in determining the strength of CoDesign. Such terminologies may be further explored in the future research to see their relevance and reliability. The process of Co-Design is context-specific. This paper sees the term "Urban Co-Design" is apt to call the process of CoDesign within the field of Urban Design.

\section{References}

Albinsson, L, Lind, M. and Forsgren, O., (2007). CoDesign: an approach to border-crossing, network innovation, in Cunningham P. and Cunningham, M. (Eds) Expanding the knowledge economy: issues, application, case study. Amsterdam: IOS Press.

Barrie, J. and Edwards, M. (2013). Co-Design -more than post-its and goodwill. Retrieved from https://www.slideshare.net/DMA_Canberra/dmapresentation-13-1120.

Chisholm, J. (2017, 30 September). What is Co-Design? Retrieved from http://www.designforeurope.eu/what-codesign

Day, C. and Parnel, R. (2003). Consensus Design. Burlington, MA: Architectural Press.

Hagen, P. (2012). Doing Co-Design. Retrieved from https://www.slideshare.net/pennyhagen/hagenrowlandcodesign-ux-australiaupload

Myers, T. (2012). Co-Design for beginners. Retrieved from https://www.slideshare.net/Optimal.Usability/co-designfor-beginners-13675913

Raharjo, W. (1993). Towards an integrated model of architectural education in Indonesia. Unpublished Master of Architecture dissertation. Halifax, NS: Technical University of Nova Scotia.

Rodriguez, M. and Ästrand, J. (1996). Organized small-scale self-help housing. Building Issues, Volume 8 Number 4, pp.-pp. 4-24

Schön, D.A. (1987). Educating the reflective practitioner: toward a new design for teaching and learning in the professions. San Francisco, CA: Jossey-Bass Publishers. 